\title{
Outbreak of COVID-19 - an urgent need for good science to silence our fears?
}

\section{Lum LHW, Tambyah PA}

Singapore Med J 2020; 61(2): 55-57; https://doi.org/10.11622/smedj.2020018

On Page 56, Fig. 1, the following description for 7 Jan 2020 was omitted: "The genetic sequence of the probable causative virus is published". The online version of the article reflects the corrected figure.
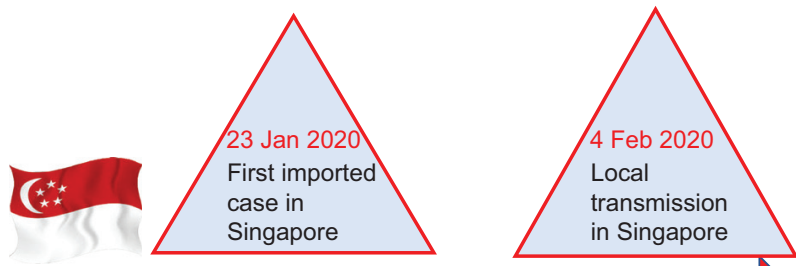

SINGAPORE

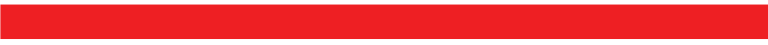

Thailand confirms

$$
\begin{aligned}
& \text { first case of } \\
& \text { COVID-19 }
\end{aligned}
$$

transmission transmis

ansmission in

outside of China

tham

Taiwan, Japan

and Germany

Philippines

1

13 Jan 2020

28 Jan 2020

first death

THE

WORLD

outside China
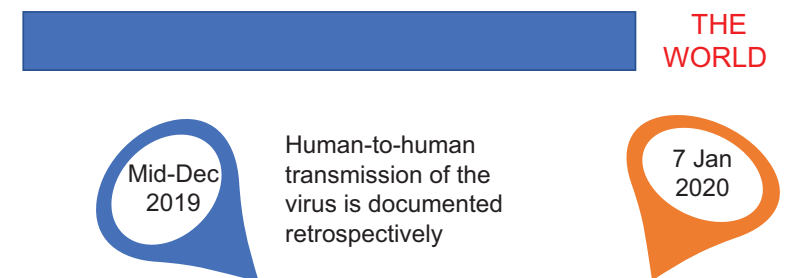

The genetic

sequence of the

probable causative

virus is published

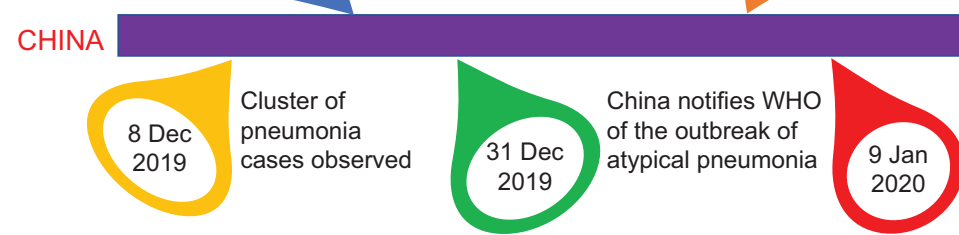

China reports first death in a 61-year-old

man with chronic liver disease who died

of respiratory failure from severe

pneumonia 